\title{
Artificial Insemination Using Preserved Spermatophores in the Palaemonid Shrimp Macrobrachium rosenbergii
}

\author{
Seinen CHOw* \\ (Received May 10, 1982)
}

\begin{abstract}
Spermatophores were removed from the sternum of female Macrobrachium rosenbergii immediately after mating and preserved in Ringer solution at $2^{\circ} \mathrm{C}$ or room temperature. After certain periods of preservation, the spermatophores, which had lost their adherence, were attached to the sternum of other females 10-15 hours after prespawning molt, using quiek set adhesive $\alpha$-cyanoacrylate as a glue. Spermatophores preserved for up to at least 17 hours at room temperatures and up to four days at $2^{\circ} \mathrm{C}$ resulted in successful fertilization and hatching. In spermatophores preserved for longer periods at $2^{\circ} \mathrm{C}$ the protective and adhesive matrices of the spermatophore degenerated greatly and were subject to damage by the propagation of bacilli, resulting in the failure of fertilization unless the preserving medium was renewed every two days.
\end{abstract}

Artificial insemination has been attempted for several species of the palaemonid shrimp genus Marcobrachium with the purpose of artificial hybridization. ${ }^{1,2)}$ Spermatophores used in these experiments were mostly fresh, sticky ones squeezed out artificially from the vasa deferentia. Artificial insemination with preserved spermatophores has not been conducted largely because the spermatophore of palaemonids rapidly loses its adherence when exposed to moisture after ejaculation. In this study I developed a simple technique of artificial insemination using preserved spermatophores in Macrobachium rosenbergii De Man.

\section{Material and Methods}

Adult Macrobrachium rosenbergii of both sexes were stocked individually in freshwater aquaria at water temperatures of $25^{\circ}-29^{\circ} \mathrm{C}$. Mating was induced by introducing a female, which recently experienced prespawning molt, into an aquarium containing a male. Artificial sea water prepared according to HERBsT's prescription and diluted to $42-50 \%$ solution was used as Ringer solution for spermatophore preservation. Fertilization was confirmed by observing cleavage two to three days after oviposition.

\section{Results}

Spermatophore Preservation
Immediately after mating, spermatophores attached to the sternum of females were carefully removed. They were washed with Ringer solution and kept in $50-\mathrm{m} l$ vials filled with Ringer solution at $2^{\circ} \mathrm{C}$ or room temperatures (ca. $20^{\circ}-$ $25^{\circ} \mathrm{C}$ ).

Under these preserving conditions the protective and adhesive matrices of the spermatophore (see CHow et $a l^{3}$ ) gradually swelled, and the adhesive matrix became slightly hardened. No other visible changes were observed during the first 24 hours of preservation at all temperature conditions. These matrices began to degenerate, becoming brittle and/or decayed, 3 to 4 days after preservation at $2^{\circ} \mathrm{C}$. Preservation at room temperatures was attempted only up to 17 hours. Bacilli had also propagated on the matrices by that time due to the manipulation without asepsis. The porpagation of bacilli was prevented to some extent by renewing the preserving medium every two days. At $2^{\circ} \mathrm{C}$, the matrices began to break up and the sperm inside the began to shed seven days after preservation. Most part of sperm was lost 10 days after preservation.

\section{Artificial Insemination}

Spermatophores newly deposited on the sternum of females were removed and replaced with preserved spermatophores. Females which did not experience mating and hence held no spermatophores usually removed "foreing substances" from their sternum, but those holding spermato-

* Research Laboratory of Fisheries Resources, Tokyo University of Fisheries, Konan-4, Minato, Tokyo 108, Japan. (張 成年：東京水産大学水産资源研究施設)。 
Table 1. Results of artificial insemination using preserved spermatophores

\begin{tabular}{|c|c|c|c|c|c|}
\hline $\begin{array}{l}\text { Spermatophore } \\
\text { specimen } \\
\text { No. }\end{array}$ & $\begin{array}{c}\text { Period of } \\
\text { preservation } \\
\text { (hr) }\end{array}$ & $\begin{array}{l}\text { Basic medium } \\
(\% \text { s.w. })\end{array}$ & $\begin{array}{l}\text { Temp. } \\
\left({ }^{\circ} \mathrm{C}\right)\end{array}$ & Fertilization & Hatching \\
\hline 1 & 0.25 & 50 & room temp. & fertilized & hatched \\
\hline 2 & 2 & $"$ & $" \Rightarrow$ & " & $n$ \\
\hline 3 & 11 & 42 & 2 & $"$ & $n$ \\
\hline 4 & 12 & 50 & $\cdots "$ & $"$ & $"$ \\
\hline 5 & 17 & $n$ & room temp. & $\Rightarrow$ & $n$ \\
\hline 6 & 18 & $"$ & 2 & $"$ & $n$ \\
\hline 7 & 23 & $"$ & $n$ & " & in \\
\hline 8 & 90 & $42^{*}$ & $n$ & not fertilized & (1) \\
\hline 9 & 95 & 50 & s & fertilized & hatched \\
\hline 10 & 155 & $"$ & $"$ & not fertilized & - \\
\hline 11 & 167 & $42^{*}$ & 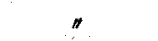 & fertilized & not hatched \\
\hline 12 & 216 & $n^{*}$ & $"$ & " & $n$ \\
\hline 13 & 243 & 50 & $"$ & not fertilized & - \\
\hline
\end{tabular}

* Medium was changed every two days.

phores readily accepted substitutes. For attaching preserved, non-adhesive spermatophores to the sternum, quick set adhesive $\alpha$-cyanoacrylate (commercial name, Aron Alpha) was found to be an excellent glue. It was necessary to remove moisture from the spermatophore and sternum by carefully wiping them on cloth or cotton. Spermatophores were attached with their side of adhesive matrix facing the sternum as seen in natural spermatophore transfer. ${ }^{2,3)}$ Females 10 to 15 hours after prespawning molt was suitable for the artificial attachment of preserved spermatophores, since their exoskeleton became somewhat hardened by that time and facilitated attachment with a glue.

Spermatophores preserved for up to 17 hours at room temperature and for up to 95 hours at $2^{\circ} \mathrm{C}$ resulted in successful fertilization and hatching, except for one case in which the spermatophore seems to have fallen off from the female's sternum (Table 1). It was not examined whether spermatophores preserved for a longer period at room temperature can lead to successful results. Fertilization did not occur in a trail with a spermatophore preserved for 155 hours at $2^{\circ} \mathrm{C}$ (Table 1 ). Whereas fertilization was confirmed in two cases using spermatophores preserved for longer periods (167 and 216 hours) where the preserving medium was renewed every two days (Table 1). In these two cases, however, the majority of berried eggs were not fertilized, and fertilized eggs fell off together with unfertilized eggs within a week. Transfer of a spermatophore preserved for 243 hours resulted in a complete failure in fertilization.

\section{Discussion}

Successful fertilization confirmed in 10 cases of a total of 13 trials (Table 1) indicates that the use of the glue is not harmful for oviposition and fertilization.

The results of artificial insemination in this study suggest that the degeneration of spermatophoric matrices causes the coming off of the spermatophore from the sternum as well as the degeneration of sperm. It is also obvious that the propagation of bacilli accelerates the degeneration of matrices. As seen in the cases of insemination with spermatophores for which preserving medium was renewed every two days (specimens 11 and 13 in Table 1), the suppression of bacillus propagation will certainly slow the degeneration of matrices and improve insemination results. If the preserving medium is improved by partly changing the composition of Ringer solution and adding aseptics and antibiotics to the medium, successful fertilization and hatching can be expected using spermatophores preserved for much longer periods than in this study. In natural conditions some macrurans hold spermatophores in the seminal receptacle or on the ventral thorax even for months without spoiling the activity of sperm. ${ }^{4, b)}$

\section{Acknowledgments}

I wish to thank Drs. Y. OGasawara and Y. TAKI for their useful criticism and advice in the manuscript. 


\section{References}

1) S Dobkin, W. P. Azzinaro, and J. VAN MontrRans: Proc. World Mariculture Soc., 5, 51-62 (1974).

2) P. A. SAndifer and T. I. J. Smith: Proc. World
Mariculture Soc., 10, 403-418 (1979).

3) S. Chow, Y. Ogasawara, and Y. TAKI: Bull. Japan. Soc. Sci. Fish., 48, 177-183 (1982).

4) P. F. BERRY: Invest. Rep. Oceanog. Res. Inst. 24, 1-16 (1970).

5) W. Templeman: Contr. Canadian Biol. Fisheries, 8, 422-432 (1934). 